\title{
ESTUDIO SOBRE EL CUMPLIMIENTO DE LA SENTENCIA MASACRE DE MAPIRIPÁN CONTRA COLOMBIA*
}

\author{
Tania Giovanna Vivas Barrera** \\ Estefanía Toro Barragán***
}

Fecha de recepción: 26 de noviembre de 2014

Fecha de evaluación: 8 de mayo de 2015

Fecha de aprobación: 18 de agosto de 2015

Artículo de reflexión

DOI: http://dx.doi.org/10.18359/prole.1678

Forma de citación: Vivas, T. \& Toro, E. (2016). Análisis de caso: estudio sobre el cumplimiento de la sentencia masacre de Mapiripán contra Colombia. Revista Prolegómenos Derechos y Valores, 19, 37, 37-56. DOI: http://dx.doi. org/10.18359/prole.1678

\section{Resumen}

Este artículo presenta los resultados del análisis del cumplimiento de las condenas ordenadas en la sentencia de la masacre de Mapiripán contra Colombia. El caso evidencia una particularidad en el análisis probatorio sobre la violación de derechos humanos y en el reconocimiento de la calidad de víctimas, tales peculiaridades han repercutido en la etapa de cumplimiento de las condenas contra el Estado colombiano. La problemática investigativa consiste por tanto en estudiar la inconsistencia probatoria revelada con la demostración de falsas víctimas reconocidas en la sentencia. Todas, situaciones que trascienden en el examen de las reglas que rigen el acervo probatorio ante la Corte Interamericana de Derechos Humanos y las especiales circunstancias del cumplimiento de las órdenes de la sentencia.

\section{Palabras clave:}

Mapiripán, Corte Interamericana de Derechos Humanos, derechos humanos, reparación integral, cumplimiento de sentencias.

\footnotetext{
Artículo de investigación científica y tecnológica, avance de investigación del proyecto de investigación "Cumplimiento de las sentencias de la Corte Interamericana de Derechos Humanos: revisión del caso colombiano en perspectiva comparada" del Grupo de Investigación "Personas, Instituciones y Exigencias de Justicia", vinculado al Centro de Investigaciones Sociojurídicas de la Facultad de Derecho de la Universidad Católica de Colombia. Las autoras hacen un especial agradecimiento a los estudiantes miembros del semillero "Observatorio en Justicia Constitucional y Derechos Humanos" que apoyaron la investigación: Albert José Campo Camargo, Johana Álvarez Rincón y Lizeth Paola Moreno Molina.

* Estudiante de doctorado en Derecho Público de la Universidad de Pau, Aquitania, Francia. Magíster en Derecho Público de la Universidad Lyon 3, Lyon, Francia; magíster en Derechos Humanos de la Universidad de Grenoble 2 Pierre Mendès-France, Grenoble, Francia; abogada y especialista en Derecho Constitucional de la Universidad Nacional de Colombia, Bogotá, Colombia. Docente investigadora de la Universidad Católica de Colombia en materia de derechos humanos, miembro del Grupo de Investigación "Personas, Instituciones y Exigencias de Justicia". Correo electrónico: tgvivas@ucatolica.edu.co

*** Estudiante de Derecho de la Universidad Católica de Colombia, Bogotá, Colombia. Miembro del Semillero de Investigación "Observatorio en Justicia Constitucional y Derechos Humanos" adscrito al Grupo de Investigación "Personas, Instituciones y Exigencias de Justicia". Correo electrónico: etoro30@ucatolica.edu.co
} 


\title{
STUDY ABOUT THE ACCOMPLISHMENT OF THE SENTENCE OF MAPIRIPÁN MASSACRE AGAINST COLOMBIA
}

\begin{abstract}
Summary
This article submits the analysis results of the accomplishment of condemnations demanded in the sentence of Mapiripán massacre against Colombia. The case evidences a particularity in the probative analysis about violation of human rights and the acknowledgment of the quality of victims; such peculiarities have impacted in the stage of accomplishment of condemnations against Colombian government. Therefore, the investigative problems consist in studying the probative inconsistence revealed with the showing of false victims acknowledged in the sentence. All of this, situations that transcend in the exam of the rules of the probative evidence before the Corte Interamericana de Derechos Humanos and the special circumstances of the accomplishment of the sentence commands.
\end{abstract}

\section{Keywords:}

Mapiripan, Corte Interamericana de Derechos Humanos, human rights, integral reparation, sentences accomplishment.

\section{ESTUDO SOBRE O CUMPRIMENTO DA SENTENÇA RELATIVA AO MASSACRE DE MAPIRIPÁN CONTRA A COLÔMBIA}

\begin{abstract}
Resumo
Este artigo apresenta os resultados da análise das condenações definidas pelas sentenças relativas ao massacre de Mapiripán contra o Estado Colombiano. O caso evidencia uma particularidade na análise probatória sobre a violação dos direitos humanos ao se reconhecer algumas peculiaridades com relação às vítimas, peculiaridades estas que repercutiram durante o cumprimento das condenações contra o estado colombiano. A problemática investigativa consiste no estudo da inconsistência probatória revelada com a revelação de falsas vítimas durante o pronunciamento da sentença. Todas estas são situações que transcendem o exame das regras que regem o acervo probatório da Corte Interamericana de Direitos Humanos, e as circunstâncias especiais do comprimento das ordens consequentes das sentenças.
\end{abstract}

\section{Palavras-chave:}

Mapiripán, Corte Interamericana de Direitos Humanos, direitos humanos, reparação integral, cumprimento de sentenças

\section{Introducción}

El artículo presenta los resultados de la investigación sobre el caso de la masacre de Mapiripán contra Colombia. El estudio se hace en el marco del proyecto de investigación sobre el establecimiento del panorama comparado de los niveles de cumplimiento de las sentencias dictadas por la Corte Interamericana de Derechos Humanos (en adelante Corte o Corte IDH) y, pretende, efectuar un examen particularizado de una sentencia que muestra notables dificultades en la realización de las sanciones impuestas, por la tacha de falsedad en la etapa de ejecución de las condenas de algunas víctimas tenidas por tales por la propia Corte. 
El objetivo del análisis de caso será establecer el grado de cumplimiento de la sentencia Masacre de Mapiripán us. Colombia. Para lograr tal propósito, es necesario definir en primera instancia la existencia de una estructura probatoria diseñada jurisprudencialmente en el marco normativo del Estatuto de la Corte, lo que explicaría el peso probatorio del allanamiento de responsabilidad internacional del Estado sobre ciertos hechos y la aceptación de documentos de prensa como prueba para definir el número de víctimas.

El peso de la aceptación del Estado colombiano del número de víctimas reconocidas por la Corte, debe revisarse de acuerdo con lo que la Corte valora como prueba, puntualmente definida a través de sus diferentes fallos contenciosos. Lo que permitirá precisar la repercusión del análisis probatorio del erróneo reconocimiento del estatus de víctimas a quienes no tenían tal calidad, sobre el cumplimiento de las condenas y órdenes de reparación impuestas.

\section{A. Metodología}

La validez metodológica de los estudios de caso desde el punto de vista de los derechos humanos es ampliamente utilizada y muy común desde la creciente crítica del relativismo cultural al universalismo de los derechos humanos en sociedades no occidentales (Marquardt, 2014). Evidentemente, si se efectuara lo que para Todd Landman (2011) es uno de los métodos disponibles para desarrollar estudios comparados, esto es, un estudio de caso, puede en estricto sentido entenderse también como un estudio de derecho comparado $^{1}$ (Marquardt, 2009; Vivas, 2013).

Para Landman (2011) existen tres niveles del método comparado que se pueden usar dependiendo de la investigación, los recursos y el tiempo del investigador, por lo que también se deben tener en cuenta factores como la abstracción del tema y la cantidad de países que se vayan a comparar. Explica Landman (2011) con base en Mair que según el nivel de abstracción y la

1 Sobre los métodos comparados véase Marquardt (2009) y Vivas (2013). cantidad de países, se puede determinar qué método comparativo emplear (véase gráfica 1).

Gráfica 1. Métodos de comparación

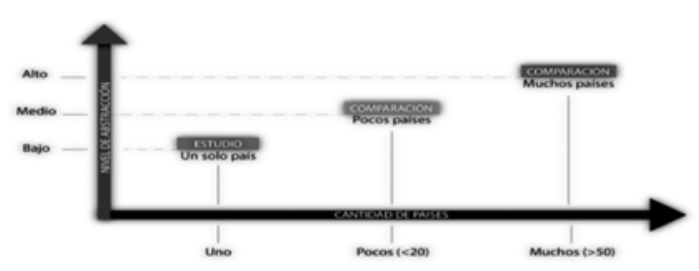

Fuente: Landman (2011, p. 50).

De acuerdo con Landman (2011) el estudio de un solo caso es el más intensivo, pues exige profundidad en el análisis de los eventos detallados del caso. Advierte el autor además, que los estudios de una sola nación -un solo caso de un país específico- resultan importantes dado que "manejan conceptos aplicables a otros países, desarrollan conceptos nuevos que resultan de aplicación a otros países y/o enmarcan estudios en un contexto comparado" (Landman, 2011, p. 51).

La investigación en la que se enmarca este artículo, pretende efectuar un análisis del cumplimiento de las sentencias de los veinte Estados ${ }^{2}$ que a diciembre de $2013^{3}$ aceptaron la jurisdicción contenciosa de la Corte IDH, y del cual ya se han obtenido resultados que están en curso de ser publicados. Tal investigación encajaría según el modelo de Landman, en un estudio comparado de pocos países, teniendo en cuenta el conjunto de Estados que admitieron la competencia de la Corte para llevar casos individuales y sancionar al Estado por la violación de la Convención Americana sobre Derechos Humanos.

2 Estos son: Argentina, Barbados, Bolivia, Brasil, Chile, Colombia, Costa Rica, Ecuador, Surinam, El Salvador, Guatemala, Haití, Honduras, México, Nicaragua, Panamá, Paraguay, Perú, República Dominicana y Uruguay.

3 Según el informe de Firmas y Ratificaciones de la Convención, disponible en el sitio oficial del Departamento de Derecho Internacional de la Organización de los Estados Americanos. Casos Velásquez Rodríguez vs. Honduras; Godínez Cruz vs. Honduras y Fairén Garbi y Solís Corrales vs. Honduras (Informe anual de la Corte IDH, 1988, párrs. 101, 127-131). 
El resultado que se presenta aquí, responde a un análisis de un solo caso y un solo país, lo que permitirá efectuar un examen concreto y profundo de las circunstancias que explicarían el nivel de cumplimiento del Estado colombiano por las condenas recibidas en el caso de la masacre de Mapiripán. Los resultados expuestos en este artículo surgen de la revisión documental de las resoluciones de ejecución de cumplimiento del caso y de los informes anuales de la Corte IDH donde reporta el cumplimiento de sus propias decisiones.

\section{B. Los criterios probatorios consi- derados por el Sistema Interameri- cano de Derechos Humanos}

Determinar el peso de ciertos medios probatorios para la Corte IDH en el momento de declarar responsable a un Estado -principalmente el valor del allanamiento por parte de un Estado-, nos ayudará a establecer si se puede hablar de un diseño probatorio en el Sistema Interamericano de Derechos Humanos (SIDH), entendido este como el sistema integrado por los órganos directores de la admisión, recolección y valoración de la prueba por violaciones de derechos humanos, es decir, la Comisión y la Corte IDH.

La finalidad de la prueba en el SIDH es la de establecer si un Estado que ha aceptado las obligaciones incorporadas en la Convención, es responsable internacionalmente por vulnerar o violar los derechos consagrados en esta.

En el proceso ante la Comisión y la Corte IDH al investigar un Estado, se pueden acceder a varios medios probatorios como: testimonios, dictámenes periciales y documentos que se puedan recaudar, incluyendo las noticias publicadas en la prensa, como sucedió en el caso de la masacre de Mapiripán. Pero, ¿̇cuál es el verdadero peso que le da la Corte IDH a estos medios probatorios? Como veremos más adelante en la discusión en torno a las pruebas en el caso particular de la Masacre de Mapiripán vs. Colombia, la Corte IDH tiene muy presente los testimonios y las declaraciones brindadas por las presuntas víctimas, pues las pruebas allegadas al proceso básicamente son las documentales, testimoniales y periciales. Y las que tienen mayor peso son las testimoniales porque en cantidad y en calidad, al parecer son más dinámicas que las demás.

Decimos que son más dinámicas por el acceso que tienen las partes para recaudarlas, en este caso, la Comisión Interamericana de Derechos Humanos (CIDH) y los representantes de las víctimas: el Colectivo de Abogados José Alvear Restrepo y el Centro por la Justicia y el Derecho Internacional; en efecto, resulta más fácil acceder a testimonios que a documentos institucionales que protegen entidades del Estado que se investiga.

Pero si el Estado que tiene mayores posibilidades para probar determinadas conductas no colabora en el proceso, se generaría una debilidad probatoria en el mismo si se considerara de mayor peso demostrativo a la prueba documental sobre la testimonial, teniendo en cuenta la dificultad de acceso para la CIDH y para los representantes de víctimas.

En el proceso de considerar el acceso a la prueba que tienen las partes a documentos, peritajes o testimonios y analizando así mismo el peso probatorio de estos, es importante señalar y responder a la cuestión de si en el SIDH existe algún diseño probatorio y si es así, cómo funciona este y qué tanta relevancia tiene el fenómeno del allanamiento en relación con la valoración probatoria.

\section{C. ¿Existe una construcción jurispru- dencial que pudiera considerarse un diseño de análisis probatorio de la Corte Interamericana de Derechos Humanos?}

La Corte IDH no se ha quedado estática en la búsqueda de un sistema que le ayude a valorar de mejor forma el material probatorio, enfren- 
tando la responsabilidad de evaluar e interpretar la naturaleza de los hechos y la debilidad del material probatorio. Es por ello que entraremos a estudiar cómo ha ido evolucionando el reglamento de la Corte IDH, conforme con sus necesidades, visibilizando sus propios constructos jurisprudenciales.

Si bien la Corte realiza el examen de las pruebas a la luz de lo establecido en el reglamento, ha ido desarrollando consideraciones aplicables a casos concretos y que estimamos pueden concebirse como un diseño de estructura probatoria específica.

Durante la vigencia del primer reglamento de la Corte IDH (1980-1991) y del análisis de las consideraciones en los casos más representativos de dicho periodo ${ }^{1}$ se pueden recoger las siguientes observaciones: la Corte, cuando alguna de las partes recusaba algún testimonio podía rechazar la recusación y apreciar la declaración rendida por la persona. Como no están taxativamente señalados en el reglamento, la Corte creó criterios para valorar la prueba. Existen diferentes graduaciones que dependen de la naturaleza, gravedad y carácter del litigio.

Cuando se trata de casos de desaparición forzada atribuibles a un Estado, la Corte para valorar la prueba, optó por darle una gravedad especial. Apoyada en tribunales internacionales, la Corte juzgó que la prueba directa (testimonial o documental) no es la única que se puede considerar para dictar sentencia, ya que también toma en cuenta la prueba circunstancial, los indicios y las presunciones, siempre y cuando de allí pueda inferirse conclusiones consistentes sobre los hechos.

Una de las características de la desaparición forzada es la supresión de todo elemento probatorio, por tanto, la prueba indiciaria o presunta toma gran importancia. También en este periodo la Corte interpretó el silencio del demandado o su contestación elusiva o ambigua como la aceptación de los hechos expuestos en la demanda. Pero la Corte trataba de suplir esas deficiencias procesales, por ejemplo, admitiendo pruebas que eran presentadas en forma extemporánea $y$ ordenando otras de oficio.

La particularidad que enmarca la desaparición forzada no solo ha efectuado variaciones en el dispositivo probatorio, además se ha comprendido como fundamento fáctico de la construcción de la jurisprudencia de la Corte del derecho a la verdad como componente del acceso a la justicia y como elemento constitutivo de la medida de reparación (Amaya, 2007).

Es destacable el hecho de que la Corte, en el caso Fairén Garbi y Solís Corrales vs. Honduras, se remite a lo probado en casos anteriores en el tema del contexto que se vivía dentro del país, en cuanto a la desaparición forzada y la ineficacia de los recursos, por lo que da automáticamente por probado los hechos (respecto al contexto, no al caso en particular).

A continuación, el periodo en que rigió el segundo reglamento (1992-1996), se destaca lo dicho por la Corte en el caso Neira Alegría y otros vs. Perú (1995, párr. 65), donde considera que cuando la violación a los derechos humanos se ha realizado dentro de un centro penal a cargo del Estado, o que la investigación estuvo bajo control exclusivo del Gobierno, la carga de la prueba recae sobre el demandado, es decir, sobre el Estado. Esto es porque en muchos casos el demandante no puede aportar pruebas sin la cooperación del Estado. La Corte además reiteró, en el caso Gangaram Panday us. Surinam que

[...] en ejercicio de su función jurisdiccional, tratándose de la obtención y valoración de las pruebas necesarias para la decisión de los casos que conoce puede, en determinadas circunstancias, utilizar tanto las pruebas circunstanciales como los indicios o las presunciones como base de sus pronunciamientos, cuando de aquellas puedan inferirse conclusiones consistentes sobre los hechos, en particular cuando el Estado demandado haya asumido una conducta renuente en sus actuaciones ante la Corte (1994, párr. 49). 
En el mismo caso, la Corte reparó en que si el Estado omite suministrar los documentos requeridos como prueba para mejor proceder, se infiere que son ciertos los hechos sobre los que versaba la prueba, esto por la actitud del Estado. En los casos de desaparición forzada, cuando ha pasado un tiempo razonable sin tener noticia del desaparecido a partir del día en que ocurrieron los hechos, la Corte optó por estimar que esa situación lleva a inducir el fallecimiento de la persona, a darlo como probado, como se da en el caso Caballero Delgado y Santana vs. Colombia (Corte IDH, 1995, párr. 53b), en donde habían transcurrido seis años.

Entre 1997 y el 2000, en vigencia del tercer reglamento, de las decisiones se puede recoger que la propia Corte comienza a ser más estructurada en cuanto a la valoración de la prueba, y cuando se trata de documentos anexados en el escrito de la demanda que sirvan como prueba, así como declaraciones de testigos e informes periciales, y que no sean objetados, su autenticidad no se coloque en duda y tampoco sean controvertidas por el demandado, la Corte los da por válidos (Corte IDH, caso Suárez Rosero vs. Ecuador, 1997, párr. 29).

Además, cuando el Estado refuta las declaraciones de determinadas personas, argumentando que podrían tener algún interés eventual en el resultado del proceso, la Corte considera que por ese motivo no se les puede descalificar como testigos. Respecto de los testigos que son objetados, en el caso Loayza Tamayo vs. Perú, la Corte señaló que

[...] los criterios de valoración de la prueba ante un tribunal internacional de derechos humanos revisten características especiales. Este no es un tribunal penal, por lo cual, las causales de objeción de testigos no operan en la misma forma, de modo tal que la investigación de la responsabilidad internacional de un Estado por violación de derechos humanos permite a la Corte una mayor amplitud en la valoración de la prueba testimonial evacuada de acuerdo con las reglas de la lógica y de la experiencia (1997, párr. 42).

En este mismo caso, sobre el testimonio de la presunta víctima, que obviamente tiene interés directo en el resultado del caso, la Corte dijo que "debe ser valorado como indicio dentro del conjunto de pruebas" del proceso (Corte IDH, caso Loayza Tamayo vs. Perú, 1997, párr. 43). En lo que tiene que ver con el valor probatorio de documentos de prensa, la Corte estimó que

[...] si bien no tienen el carácter de prueba documental, tienen importancia en cuanto sean la manifestación de hechos públicos y notorios, y en la medida que corroboren los testimonios recibidos en el proceso respecto de las circunstancias de las detenciones y muertes de las víctimas (caso de la "Panel Blanca" [Paniagua Morales y otros] vs. Guatemala, 1998, párr. 75).

En vigencia del cuarto reglamento (2001-2003), se subraya lo dicho por la Corte en el caso de la Comunidad Mayagna (Sumo) Awas Tingni vs. Nicaragua (2001, párr. 89), en cuanto al tema de admisión de la prueba, que para tener el mayor número posible de pruebas, un criterio a tener en cuenta es la "ausencia de formalismo en la valoración de la prueba". Por ello se muestra más flexible "en la admisión y valoración de las mismas, de acuerdo con las reglas de lógica y con base en la experiencia".

Debido a esto, se tiene como criterio esencial para la valoración de la prueba, la sana crítica y el no requerimiento de formalidades en su admisión y valoración. Así también lo deja claro la Corte en el caso "La última tentación de Cristo" (Olmedo Bustos y otros) vs. Chile (2001, párr. 51), cuando expresó que meras formalidades no pueden sacrificar la justicia que se pretende obtener al acudir a un sistema procesal, sin que por ello se deje de cuidar la seguridad jurídica y el equilibrio procesal de las partes. 
De la jurisprudencia dictada por la Corte durante el tiempo de vigencia de los dos últimos reglamentos (2009 a la actualidad), vale la pena subrayar que las declaraciones de familiares de las presuntas víctimas -y que tienen interés directo en el resultado del caso- no pueden valorarse de forma aislada, sino dentro del conjunto de las pruebas del proceso. "En materia tanto de fondo como de reparaciones, las declaraciones de los familiares de las presuntas víctimas son útiles en la medida en que pueden proporcionar mayor información sobre las consecuencias de las violaciones que pudieron haber sido perpetradas" 4 .

En lo relativo a la sana crítica, la Corte expresó en el caso de los 19 comerciantes vs. Colombia que, con base en la jurisprudencia internacional, los tribunales jurisprudenciales han evitado adoptar una rígida determinación del quantum de la prueba necesaria para fundar un fallo.

Tratándose de documentos que se presentan como pruebas, pero que están incompletos o resultan ilegibles, la Corte no acepta incorporarlos al acervo probatorio (Corte IDH, caso Masacre de Las Dos Erres vs. Guatemala, 2009, párr. 60). Pero sí admite las declaraciones juradas que no son rendidas ante fedatario público, siempre y cuando no se afecte la seguridad jurídica y el equilibrio procesal entre las partes (Corte IDH, caso Masacre de Las Dos Erres vs. Guatemala, 2009, párr. 69).

En casos como Masacre de Santo Domingo vs. Colombia y Artavia Murillo y otros ("Fecundación in vitro") vs. Costa Rica, la Corte desarrolló un poco más el tema de las notas de prensa. Solo acepta los documentos que se encuentran completos, o que al menos permitan constatar su fuente y fecha de publicación. En el asunto

4 Entre las sentencias que tratan el tema referimos las siguientes: de 5 de julio de 2004, serie C-109, párrs. 65 y 79 (caso 19 comerciantes vs. Colombia); de 2 de septiembre de 2004, serie C-112, párr. 97 (caso Instituto de Reeducación del Menor vs. Paraguay) y de 27 de noviembre de 2003, serie C-103, párrs. 53 y 54 (caso Maritza Urrutia vs. Guatemala). de documentos señalados por medio de enlaces electrónicos,

[...] el tribunal ha establecido que si una parte proporciona al menos el enlace electrónico directo del documento que cita como prueba y es posible acceder a este, no se ve afectada la seguridad jurídica ni el equilibrio procesal, porque es inmediatamente localizable por el tribunal y por las otras partes ${ }^{5}$.

Luego de haber analizado las modificaciones del reglamento que sirvieron para que la Corte cuente con más acceso al material probatorio, lo cual se complementa con una construcción jurisprudencial que ha asentado los principios que rigen en materia de la búsqueda, admisión y valoración de la prueba, resulta correcto decir que al interior de la Corte existe un diseño propio de análisis probatorio, sustentado en la necesidad de esclarecer lo mejor posible los hechos que ayuden a condenar graves violaciones de derechos humanos.

\section{Análisis del caso Mapiripán vs. Colombia, antecedentes}

La masacre de Mapiripán se cuenta entre los hechos más violentos y de mayor controversia en nuestro país. Mapiripán es un municipio de reducida población y donde se ubicaron los principales asentamientos guerrilleros y cultivos de coca y marihuana. En la madrugada del 14 de julio de 1997 irrumpió aproximadamente un centenar de paramilitares rodeando al municipio por agua y tierra (Huertas, 2006), con el objetivo de atacar a los guerrilleros de las Farc allí establecidos y recuperar el control sobre el territorio (Corte IDH, caso Masacre de Mapiripán vs. Colombia, 2005, p. 43).

\footnotetext{
La Corte IDH ha venido desarrollando su aceptación probatoria de notas periodísticas, situación que se refleja en los siguientes casos: Masacre de Santo Domingo vs. Colombia (sentencia de 30 de noviembre de 2012, serie C-259, párr. 44) y Artavia Murillo y otros ("Fecundación in vitro") vs. Costa Rica (CIDH, sentencia de 28 de noviembre de 2012, serie C-257, párrs. 47 y 48).
} 
Sin embargo, el operativo inicia en el departamento de Antioquia, en la zona del Urabá desde los aeropuertos de Necoclí y Apartadó hasta su traslado a Mapiripán, de ese hecho, se conoce que las Fuerzas Militares dieron cabida a paramilitares para que ellos fueran llevados hasta Mapiripán portando uniformes del Ejército Nacional y armados con dotación oficial ${ }^{6}$. Los paramilitares emplearon diferentes formas de tortura: descuartizaron varios cuerpos y dego-

6 Es pertinente aclarar que en Mapiripán sí había presencia estatal, tal y como queda demostrado con la siguiente información: en el departamento del Meta y en las zonas aledañas, estaban establecidas posiciones estratégicas del Ejército: en San José del Guaviare, se encontraba la jurisdicción del municipio suscrita al Batallón Joaquín París a cargo del entonces coronel Carlos Ávila, quien estaba de vacaciones y había sido reemplazado por el mayor Hernán Orozco, este batallón a su vez estaba adscrito a la VII Brigada del Ejército Nacional de Colombia con sede en Villavicencio, bajo el mando del general Jaime Humberto Uscátegui; también se encontraba la Brigada Móvil II que era un comando de operaciones contraguerrilla (Corte IDH, caso Masacre de Mapiripán vs. Colombia, sentencia de 15 de septiembre de 2005, p. 44). Además se halló que entre los municipios de Mapiripán y Charras, había un asentamiento de la Infantería de Marina, razones por las cuales es de resaltar que Mapiripán tenía suficiente protección por parte de las Fuerzas Militares desde cualquier punto estratégico de la región.

Así pues, a la llegada de los paramilitares al aeropuerto de San José del Guaviare, el Ejército autorizó a estos para que se transportaran vía aérea y marítima desde allí para reunirse en el camino con otro grupo de paramilitares y dar inicio a su operativo.

Días antes, el jefe paramilitar Carlos Castaño Gil aseguró que dentro de Mapiripán estaban guerrilleros de las Farc y que a las personas que los protegieran o les pagara a este grupo responderían y serían objetivo militar (Corte IDH, caso Masacre de Mapiripán vs. Colombia, sentencia de 15 de septiembre de 2005, p. 45) conociendo estos anuncios, la Fuerza Pública decidió hacer caso omiso y en su lugar llevó a cabo otras operaciones para capturar guerrilleros en zonas cercanas a Mapiripán. El día de la masacre, "El juez promiscuo municipal de Mapiripán, se comunicó con la Procuraduría Delegada para Derechos Humanos y con el Tribunal Superior del Distrito Judicial del Meta, el cual se abstuvo de realizar actuaciones investigativas" (Corte IDH, caso Masacre de Mapiripán vs. Colombia, sentencia de 15 de septiembre de 2005, p. 46).

La masacre perduró por cinco días y en el análisis realizado se hallaron 49 víctimas sin contar aquellas que no fueron identificadas o que sus cuerpos aún están desaparecidos. llaron algunas de sus víctimas, sembrando el terror en la población hasta el punto, según lo relatan algunos testigos, de haber jugado fútbol con la cabeza de una de las víctimas señalada como auxiliadora de la guerrilla.

Solo hasta el 23 de julio, luego de nueve días de terror, llegan al municipio delegados de la Fiscalía General de la Nación y de la Unidad Nacional de Derechos Humanos junto con miembros de la Fuerza Pública para realizar una valoración de lo ocurrido, cuando ya gran parte de las pruebas se había ocultado ${ }^{7}$. Conocida la incursión de paramilitares se da inicio a una investigación de todos los acontecimientos, luego de dos años de procedimientos internos, el 6 de octubre de 1999 se presenta formalmente la denuncia ante la $\mathrm{CIDH}$, remitido el caso a conocimiento de la Corte el 5 de septiembre de 2003, después de solo dos años del contencioso y con un gran cantidad de medidas provisionales, se condena al Estado colombiano el 15 de septiembre de 2005.
$7 \quad$ El hecho de que las AUC desaparecieran muchos de los cuerpos y los tiraran al río, fue un grave delito en contra de sus familiares y de la nación, y de aquellos principios que gobiernan nuestra nación como la dignidad humana, impidiendo además una tarea efectiva de identificación de las víctimas, porque algunas de ellas hoy en día están sin reconocer. El terror continuó hasta el 20 de julio de 1997, cuando ya la mayoría de las pruebas había sido desaparecida. 
La sentencia de fondo condena ${ }^{8}$ a Colombia por cerca de 49 víctimas por la violación

8 Se reproduce el texto completo: "La Corte declara que, - Ha cesado la controversia sobre la excepción preliminar referente a la 'aplicación indebida de los artículos 50 y 51 de la Convención Americana'.

- El Estado violó en perjuicio de cierto número de víctimas -que el propio Estado mencionó como 'aproximadamente 49'-, de las cuales han sido individualizadas los señores José Rolan Valencia, Sinaí Blanco Santamaría, Antonio María Barrera Calle, Álvaro Tovar Muñoz, Jaime Pinzón, Raúl Morales, Edwin Morales, Manuel Arévalo, Hugo Fernando Martínez Contreras, Diego Armando Martínez Contreras, Omar Patiño Vaca, Eliécer Martínez Vaca, Gustavo Caicedo Rodríguez, Enrique Pinzón López, Luis Eduardo Pinzón López, Jorge Pinzón López, José Alberto Pinzón López, Jaime Riaño Colorado y Uriel Garzón, y la señora Ana Beiba Ramírez, los derechos a la libertad personal, a la integridad personal y a la vida, consagrados en los artículos 4.1, 5.1, 5.2, 7.1 y 7.2 de la Convención, en relación con el artículo 1.1 de dicho tratado.

- El Estado violó en perjuicio de los familiares de las víctimas el derecho a la integridad personal, consagrado en [los] artículos 5.1 y 5.2 de la Convención, en relación con el artículo 1.1 de dicho tratado.

- El Estado violó en perjuicio de Hugo Fernando y Diego Armando Martínez Contreras, Carmen Johanna Jaramillo Giraldo, Gustavo Caicedo Contreras, Maryuri Caicedo Contreras, Rusbel Asdrúbal Martínez Contreras, y los hermanos Valencia Sanmiguel, a saber, Nadia Mariana, Yinda Adriana, Johanna Marina, Roland Andrés y Ronald Mayiber los derechos de los niños consagrados en el artículo 19 de la Convención, en relación con los artículos 4.1, 5.1 y 1.1 de la misma, en los términos de los párrafos 159, 160 y 163 de esta sentencia. Así mismo, el Estado violó en perjuicio de quienes fueron niños y niñas desplazados de Mapiripán, de los cuales han sido individualizados en esta sentencia Carmen Johanna Jaramillo Giraldo, Gustavo Caicedo Contreras, Maryuri Caicedo Contreras, Rusbel Asdrúbal Martínez Contreras y los hermanos Valencia Sanmiguel, a saber, Nadia Mariana, Yinda Adriana, Johanna Marina, Roland Andrés y Ronald Mayiber, los derechos de los niños consagrados en dicha disposición de la Convención, en relación con los artículos 4.1, 22.1 y 1.1 de la misma. - El Estado violó en perjuicio de Mariela Contreras Cruz, Rusbel Asdrúbal Martínez Contreras, Maryuri y Gustavo Caicedo Contreras, Zuli Herrera Contreras, Nory Giraldo de Jaramillo, Carmen Johanna Jaramillo Giraldo, Marina Sanmiguel Duarte, Nadia Mariana, Yinda Adriana, Johanna Marina, Roland Andrés y Ronald Mayiber, todos Valencia Sanmiguel, Teresa López de Pinzón y Luz Mery Pinzón López el derecho de circulación y residencia consagrado en el artículo 22.1 de la Convención, en relación con los artículos 4.1, 5.1, 19 y 1.1 de dicho tratado.

-El Estado violó en perjuicio de los familiares de las víctimas los derechos a las garantías judiciales y a la protección judicial consagrados en los artículos 8.1 y 25 de la Convención, en relación con el artículo 1.1 de la misma". de los derechos a la libertad personal, a la integridad personal y a la vida; el derecho de los niños y el derecho de circulación y residencia consagrados en los artículos 4.1, 5.1, 5.2, 7.1, 7.2 y 22.1 de la Convención, además se condenó al Estado por la violación en perjuicio de los familiares de las víctimas de los derechos a las garantías judiciales y a la protección judicial-artículos 8.1 y 25 de la Convención-. Por último se le ordena al Estado identificar $e$ individualizar a las víctimas que aún no habían sido reconocidas tanto por el Estado como por la misma Corte.

\section{E. Sobre la ejecución y cumplimiento de la sentencia}

Después de ocho años de la condena por la masacre de Mapiripán de 1997, se contaba con total cumplimiento de las órdenes de reparación pecuniaria por parte del Estado y un avance en ejecución de las demás órdenes de satisfacción y garantías de no repetición. En 2012 se dio a conocer un hecho que causó discusión de opiniones sobre la situación del caso de Mapiripán, el Estado descubrió que una de las víctimas reconocidas por la Corte, no era realmente víctima, sino que se hizo pasar como tal y persuadió a sus familiares para que rindieran versiones sobre ese hecho; así obtuvieron un lucro económico significativo a costa del Estado.

Este evento puso en tela de juicio todas las versiones dadas por quienes se consideraban víctimas. Se comprobó que algunas personas que se reportaron como asesinadas y se aceptaron por tal ante la Corte, en realidad estaban vivas o se habían unido de modo voluntario a los paramilitares. Luego del escándalo mediático, el Estado solicitó a la Corte que se efectuara una revisión de la sentencia, sin que estatutariamente existiera dicha posibilidad. La Corte interpretó la solicitud considerando la exigencia del Estado de dictar un nuevo fallo que corrigiera aquel del 2005, precisando entonces la ausencia de cualquier posibilidad de acceder a tal solicitud. 
La crítica del Estado se centraba en la revisión de las pruebas que se tomaron para la sentencia de fondo del 2005, la Corte sentó la prueba de la responsabilidad estatal sobre la aceptación de responsabilidad admitida por el Estado colombiano. El caso Mapiripán es emblemático en el estudio de la trascendencia jurídica de la aceptación de responsabilidad parcial por parte del Estado ante violaciones que examina la Corte IDH; en efecto, el Estado espera la disminución del trámite ante la Corte pero su mayor valor recae en la disminución del debate probatorio (Romero, 2009). La controversia anterior nos ubica en el centro del estudio sobre la base probatoria para la condena del 2005 y que presentamos a continuación.

\section{F. Discusión en torno a las pruebas}

\section{Pruebas aportadas durante el proceso contencioso}

Las pruebas testimoniales que constan principalmente de las declaraciones de las "presuntas víctimas" (Corte IDH, caso de la Masacre de Mapiripán vs. Colombia, 2005, p. 18 y ss.), fueron recolectadas por los representantes de las víctimas y alOlegadas a la Comisión IDH. Los testimonios narran la manera en que se suscitaron los hechos de la masacre, el sufrimiento que padecieron como familiares de las víctimas y lo que implicó la pérdida moral y material de sus familiares ${ }^{9}$.

Dentro de las pruebas documentales encontramos el concepto rendido por Luis Guillermo Pérez (abogado de derechos humanos) y los peritajes de Ana Deutsch (psicóloga) y Robin

9 Por citar un ejemplo, en el caso de Nadia Mariana Valencia, hija del señor José Rolan, su declaración relata: "Al día siguiente, el inspector y el alcalde llegaron a avisarles que los paramilitares habían matado a su padre y que su cuerpo estaba en el aeropuerto. Nunca vieron muerto a su padre, pero la gente les contó que 'lo habían degollado, habían jugado fútbol con la cabeza, y que su cabeza estaba a diez metros del cuerpo" (Corte IDH, caso de la Masacre de Mapiripán vs. Colombia, sentencia de 15 de septiembre de 2005, p. 23).
Kirk (profesional en derechos humanos) (Corte $\mathrm{IDH}$, caso de la Masacre de Mapiripán vs. Colombia, 2005, pp. 18-27); que son determinantes para indicarle a la Corte IDH, el contexto de la masacre y su implicación social y económica, esto es, la violencia histórica -y sus desastrosas consecuencias- que padece Colombia.

Se aportaron siete pruebas testimoniales y periciales ${ }^{10}$ que se rindieron directamente ante la Corte IDH en la audiencia pública; vale la pena indicar que los testigos fueron involucrados en el proceso por la Comisión IDH, los representantes de las víctimas y el Estado (Corte IDH, caso de la Masacre de Mapiripán us. Colombia, 2005 , p. 28). En dicha audiencia, una de las "presuntas víctimas" -Sra. Mariela Contreras Cruz- expresó que:

Vivía a hora y media de Mapiripán con su esposo y sus 7 hijos. Su casa era de madera; tenía electrodomésticos, ganado, gallinas, cerdos y chivos. Cuando estaban en Mapiripán sus hijos se escaparon y le contaron que habían visto pedazos de cuerpos (Corte IDH, caso de la Masacre de Mapiripán vs. Colombia. 2005, p. 29).

"Como no vio muertos a sus hijos y esposo se hace la idea que ellos están vivos; sin embargo, cree que nunca verá los cadáveres" (2005, p. 30), es así como la Sra. Contreras narra la pérdida de su compañero sentimental Gustavo Caicedo y de sus dos hijos Hugo Fernando y Diego Armando Martínez Contreras.

La Corte IDH también decidió tener en cuenta las noticias publicadas en la prensa, cuando estas

10 Los testimonios y las pruebas periciales aportadas al caso de la masacre de Mapiripán fueron rendidos por: Gustavo Morales Marín (fiscal ante la Corte Suprema de Justicia colombiana), Luz Mery Pinzón López, Mariela Contreras Cruz, Nory Giraldo de Jaramillo, Marina Sanmiguel Duarte, Viviana Barrera y el peritaje del señor Federico Andrew Guzmán (especialista en derechos humanos). 
involucren hechos notorios o de carácter público. Situación que para el caso de Mapiripán tiene plena vigencia, al considerarse como prueba la declaración del jefe del grupo paramilitar Autodefensas Unidas de Colombia (AUC), Carlos Castaño Gil, en los medios de comunicación al referirse a la masacre como "el combate más grande que han tenido las autodefensas en su historia. Nunca habíamos dado de baja a 49 miembros de las Farc" (resolución de acusación de 10 de marzo del 2003, Unidad Nacional de Derechos Humanos, expediente de anexos a la demanda, anexo 42, folio 707, citado en Corte IDH, caso de la Masacre de Mapiripán vs. Colombia, 2005, p. 49). Tasa de víctimas relevante en el momento de dictar sentencia, ya que fue la única estimación considerada "certera" por parte de la Corte IDH para indicar un número de víctimas al momento de condenar al Estado colombiano.

\section{La posición del Estado ante las pruebas y las víctimas}

El Estado colombiano indicó que en las pruebas documentales encontraba inconsistencias en cinco de ellas: testimonios que aportaron al caso: María Teresa Pinzón López, Esther Pinzón López, Sara Paola Pinzón López, Zuli Herrera Contreras y el peritaje del señor Luis Guillermo Pérez. Sin embargo, dicha observación no la tuvo en cuenta la Corte IDH, por la ausencia especialmente de pruebas sólidas para refutar la existencia de las víctimas (Uribe \& Restrepo, 2013). Si la Corte IDH o el Estado hubieran aclarado, investigado o esclarecido las ambigüedades en las mencionadas declaraciones testimoniales, el caso de la masacre de Mapiripán, habría sido más certero probatoriamente.

En cuanto a las víctimas de la masacre de Mapiripán se pudo determinar que fueron descuartizadas, desmembradas o degolladas, luego se lanzaron al río San José del Guaviare, lo que convirtió este caso en algo muy complejo de resolver para la justicia colombiana, pues no se cuenta con una clara identificación de cadáveres.
Es por esto que los testimonios de las "presuntas víctimas" es el mayor acervo probatorio de la Corte, precisamente, aquí nace la crítica contra el examen de la prueba y la adopción de veracidad y credibilidad a testimonios luego tachados de falsedad (Uribe \& Restrepo, 2013).

Según el informe de James Crawford ante la Corte, se estima que "no hay detalles específicos sobre el caso, la discusión está necesariamente dada en términos generales, será la Corte la que se ocupe en detalle de los hechos con base en la evidencia presentada por las partes, es decir, el texto no versa sobre los hechos del caso" (Corte IDH, caso de la Masacre de Mapiripán vs. Colombia, 2005, párr. 88). Con dicho fundamento el Estado colombiano aceptó la responsabilidad y se allanó en cuanto al número de víctimas generadas por los hechos del 15 al 20 de julio de 1997 en el municipio de Mapiripán, departamento del Meta.

El Estado no pudo fijar con claridad las circunstancias de desaparición o muerte de las víctimas y mucho menos la cifra de los implicados, es por esto que solicitó a la Corte IDH, que en caso de reconocer la existencia de posibles daños a favor de las víctimas que no han sido identificadas "se ordene que para efectos de recibir el pago acrediten ante las respectivas autoridades internas prueba fehaciente de su vínculo con la víctima para recibir el pago de la indemnización correspondiente" (Corte IDH, caso de la Masacre de Mapiripán vs. Colombia, 2005, p. 144). Y finalmente la Corte estableció en la parte resolutiva de la sentencia que con fundamento en el acervo probatorio se estima como parte lesionada "aproximadamente a 49 víctimas" y a todos sus familiares ${ }^{11}$, es de aclarar que el Estado colombiano se resistió a un reconocimiento

11 Entre las personas que estaban identificadas para el momento en que se dictó sentencia (15 de septiembre de 2005) se encontraban: Diego Armando Martínez Contreras (menor de edad al momento de los hechos), Gustavo Caicedo Rodríguez y Hugo Fernando Martínez Contreras (menor de edad al momento de los hechos) según las pruebas aportadas por el Colectivo de Abogados José Alvear Restrepo. 
indeterminado de víctimas (Uribe \& Restrepo, 2013) por lo que la Corte debió acudir a los datos tasados por el perpetrador alias "Mancuso", en una nota de prensa.

El día 6 de abril de 2005 la Fiscalía General de la Nación suscribió un documento en el cual señala la individualización de: Manuel Arévalo, Omar Patiño Vaca y Eliécer Martínez Vaca, información que aportó el Estado a la Corte IDH. Con esta individualización y con el compromiso expreso por parte del Estado de seguir investigando cuáles fueron las víctimas de la masacre, la Corte procedió a condenar y a decretar el resarcimiento de perjuicios y las indemnizaciones correspondientes a las que valoró como "parte lesionada".

\section{G. ¿Qué víctimas se considera- ron falsas y por qué razón?}

El 24 de febrero de 2012 el Estado colombiano solicitó a la Corte IDH revisar la sentencia que profirió el día 15 de septiembre de 2005, con el fin de que determinadas personas fueran excluidas del estatus de víctimas. El Estado pidió:

[...] que se dicte una sentencia sustitutiva de la sentencia de 15 de septiembre de 2005, en la cual se reemplacen las consideraciones, declaraciones y condenas originadas en las pruebas fraudulentas que obran en el expediente, por aquellas consideraciones y declaraciones que resulten pertinentes como consecuencia de la valoración de las pruebas nuevas, que fundamentan la revisión solicitada (Corte IDH, resolución de 23 de noviembre de 2012, caso Masacre de Mapiripán vs. Colombia).

Manifiesta que hay seis personas que no tienen real condición de víctimas, las cuales son: Diego Armando Martínez Contreras, Gustavo Caicedo Rodríguez, Manuel Arévalo, Omar Patiño Vaca, Eliécer Martínez Vaca y Hugo Fernando Martínez Contreras. El dilema aquí suscitado procesalmente, se refiere a Mariela Contreras, esposa de Gustavo Caicedo Rodríguez y madre de Hugo Fernando y Diego Armando, esta supuesta víctima confesó el primero de octubre de 2011 ante la Fiscalía 28 de la Unidad Nacional de Derechos Humanos mediante declaración en la que menciona su mala fe y se autoexcluye como víctima de la masacre de Mapiripán. Lo que dice la señora Contreras es que "sus hijos habían desaparecido en Mapiripán, pero que ella no había precisado que eso hubiese ocurrido en los hechos de julio de 1997" (Corte IDH, caso de la Masacre de Mapiripán vs. Colombia, 2005, p. 11).

La resolución de supervisión de cumplimiento de la sentencia proferida el 23 de noviembre de 2012, determinó que las seis personas en mención no tienen la real condición de víctimas de los hechos ocurridos en la masacre de Mapiripán ${ }^{12}$. Para algunos críticos de la Corte, la decisión prudente debería haberse centrado en una revisión de la sentencia condenatoria acogiendo la solicitud del Estado colombiano, corregir los errores en el número de víctimas y con ello la calidad de algunas de ellas para ser reparadas, probando su capacidad para subsanar yerros de apreciación probatoria (Uribe \& Restrepo, 2013).

12 Diego Armando Martínez Contreras fue desaparecido por los paramilitares en el año de 1999, aunque para el primero de diciembre de 2000 expidiera su documento de identidad y realizara una inscripción en puesto de votación el 14 de noviembre de 2001 (según lo indica la Registraduría Nacional del Estado Civil); Gustavo Caicedo Rodríguez, según lo dicho por la señora Mariela Contreras, murió en el Anzuelo en noviembre de 1996, antes de la masacre de Mapiripán, aunque se desconoce la razón de su muerte (Corte IDH, caso de la Masacre de Mapiripán vs. Colombia, 2005, p. 16); Manuel Arévalo es el padre del señor Argemiro Arévalo que a su vez es esposo de la señora Zuli Herrera Contreras, estos afirman que el señor Arévalo murió el día 3 de marzo de 1999 por causa natural; Omar Patiño Vaca se integró a los paramilitares y desapareció desde abril del año 2002; Eliécer Martínez Vaca fue hallado muerto en el año de 1998 en el municipio de la Cooperativa y, por último, el señor Hugo Fernando Martínez Contreras se corroboró que se encuentra con vida, habiendo ingresado a la guerrilla en 1995 y desmovilizado el 6 de agosto de 2008 (Corte IDH, caso Masacre de Mapirián vs. Colombia, supervisión de cumplimiento, 2012, pp. 17-19). 


\section{H. Cumplimiento de la sentencia}

En la sentencia del 15 de septiembre de 2005, la Corte IDH condena al Estado colombiano por violación de las siguientes obligaciones consagradas en la Convención Americana: artículo 1.1 (obligación de respetar los derechos), artículos 8.1 y 25.1 (garantías judiciales y protección judicial), artículo 4.1 (derecho a la vida), artículos 5.1 y 5.2 (derecho a la integridad personal), artículos $7.1 \mathrm{y}$ 7.2 (derecho a la libertad personal), artículo 19 (derechos de los niños) y artículo 22.1 (derecho de circulación y residencia). Precisa la Corte en su primer aparte resolutivo sobre "cierto número de víctimas -que el propio Estado mencionó como 'aproximadamente 49'" - (Corte IDH, caso de la Masacre de Mapiripán vs. Colombia, 2005, p. 179). En ese aparte resolutivo la Corte además individualiza las víctimas reconocidas por cada una de las violaciones y dicta una serie de órdenes que serán objeto de seguimiento por la misma Corte en las posteriores supervisiones de cumplimiento.

Aunque para ciertos expertos el resultado del análisis sobre el cumplimiento de las medidas sea de ineficacia total, y que por lo tanto no darían lugar a comprender un total incumplimiento de las órdenes generadas, esto en relación con la protección del derecho a la propiedad de las tierras de las personas desplazadas por la masacre y garantías de seguridad (Rodríguez, 2014). Para efectos del análisis del cumplimiento de las órdenes dictadas, se clasificaron nueve tipos de órdenes específicas, así:

1. El Estado debe investigar los hechos del caso, identificar, juzgar y sancionar a los responsables de la masacre.

2. Identificación e individualización de las víctimas de la masacre de Mapiripán y sus familiares.

3. Mecanismo oficial de seguimiento del cumplimiento de las reparaciones ordenadas.

4. Tratamiento de salud adecuado a los familiares de las víctimas.
5. Garantías estatales de seguridad para los exhabitantes del municipio de Mapiripán que decidan regresar.

6. Construcción de un monumento en memoria de las víctimas.

7. Programas de educación en derechos humanos y derecho internacional humanitario para las Fuerzas Militares.

8. Publicación de la sentencia (hechos probados, responsabilidad internacional del Estado y parte resolutiva).

9. Pago de indemnizaciones por concepto de daño materia e inmaterial, costas y gastos del proceso.

Existen cuatro resoluciones de supervisión de cumplimiento dictadas el 26 de noviembre de 2008, el 8 de julio de 2009, el 8 de febrero de 2012 y el 23 de noviembre de 2012 por la Corte IDH respecto al caso de la Masacre de Mapiripán. La primera de ellas proferida tres años después de la sentencia y la última del 23 de noviembre de 2012, siete años tras la condena al Estado colombiano sin que se concrete su ejecución total. Luego de la revisión pormenorizada de las supervisiones arriba indicadas, podemos constatar los niveles de cumplimiento por orden, y se fijan los estándares como se muestra en la tabla 1.

\section{Sobre las órdenes con cumplimiento total}

Publicación de la sentencia (hechos probados, responsabilidad internacional del Estado y parte resolutiva). En la supervisión de cumplimiento con fecha de 26 de noviembre de 2008, el Gobierno colombiano informó que

El 10 de abril de 2006 se publicó en el Diario Oficial de Colombia y en el diario de la mañana El Tiempo, en una separata adicional, con una circulación de 270.000 ejemplares, la Sección de la Sentencia denominada Hechos Probados, sin las notas al pie de página 
correspondientes, los párrafos 101 a 123 de

la Sección denominada Responsabilidad
Internacional del Estado, así como la parte resolutiva de la misma.

Tabla 1. Niveles de cumplimiento por órdenes individualizadas

\begin{tabular}{|c|c|c|c|c|}
\hline Tipo de orden & Medida & CT & $\mathrm{CP}$ & I \\
\hline Restitución & $\begin{array}{l}\text { Garantías estatales de seguridad para los exhabitantes del municipio de } \\
\text { Mapiripán que decidan regresar }\end{array}$ & & $\mathrm{x}$ & \\
\hline Rehabilitación & Tratamiento adecuado de salud a los familiares de las víctimas & & $\mathrm{x}$ & \\
\hline \multirow[t]{6}{*}{$\begin{array}{l}\text { Satisfacción y no } \\
\text { repetición }\end{array}$} & $\begin{array}{l}\text { El Estado debe investigar los hechos del caso, identificar, juzgar y sancio- } \\
\text { nar a los responsables de la masacre }\end{array}$ & & $\mathrm{x}$ & \\
\hline & Publicación de la sentencia & $\mathrm{x}$ & & \\
\hline & Construcción de un monumento en memoria de las víctimas & & $\mathrm{x}$ & \\
\hline & Identificación de las víctimas de la masacre de Mapiripán y sus familiares & & $\mathrm{x}$ & \\
\hline & $\begin{array}{l}\text { Programas de educación en derechos humanos y derecho internacional } \\
\text { humanitario para las Fuerzas Militares }\end{array}$ & $\mathrm{x}$ & & \\
\hline & $\begin{array}{l}\text { Mecanismo oficial de seguimiento del cumplimiento de las reparaciones } \\
\text { ordenadas }\end{array}$ & $\mathrm{x}$ & & \\
\hline Pecuniario & Daño material e inmaterial, costas y gastos del proceso & & $\mathrm{x}$ & \\
\hline
\end{tabular}

Convenciones: Cumplimento Total (CT), cumplimento parcial (CP), Incumplimiento (I).

Fuente: elaboración propia.

Tal información ha hecho a la Corte el reconocimiento del cumplimiento de la medida (Corte IDH, 2008).

Programas de educación en derechos humanos y derecho internacional humanitario para las Fuerzas Militares. En la supervisión de cumplimiento con fecha de 8 de julio de 2009, se reporta por el Estado colombiano que

[... ] firmó un convenio de cooperación con el Alto Comisionado de Naciones Unidas para los Derechos Humanos y se contrataron a tres consultores internacionales para que hicieran un estudio sobre la capacitación en las Fuerzas Armadas colombianas, el cual sirvió para que el Ministerio de Defensa diseñara una "Política Integral de Derechos Humanos y Derecho Internacional Humanitario" en enero de 2008. El Estado expuso en detalle las actividades por realizar en la línea de adecuación de la instrucción, subrayó el impacto que esta política de Estado había tenido y señaló, como ejemplo, que las quejas en la Procuraduría habían disminuido considerablemente en el último año. Además, informó que en el Ejército se había creado la jefatura de derechos humanos, encargada de velar porque se interiorice esta política, y que se había firmado un convenio de cooperación con el Instituto Interamericano de Derechos Humanos para supervisar el progreso en la materia.

Lo que constituye para la Corte el cumplimiento de la orden (Corte IDH, 2009).

Designar un mecanismo oficial de seguimiento del cumplimiento de las reparaciones ordenadas que operará durante dos años, en el cual tengan participación las víctimas del presente caso o los representantes que ellas designen. Ya desde la supervisión de cumplimiento con fecha de 26 de noviembre de 2008:

[...] el Estado ha informado que, mediante acta de la Comisión Intersectorial Permanente 
de Derechos Humanos suscripta el 28 de febrero de 2006, se designó el mecanismo oficial de seguimiento de las reparaciones, esto es el "MOS Mapiripán" [...]. En el acta se definen las funciones y las diferentes entidades del Estado que conformarían el mecanismo, así como varios aspectos de procedimiento.

Considerando un avance significativo la creación del organismo, restando el reporte sobre su efectivo funcionamiento teniendo en cuenta el parcial cumplimiento de la medida (Corte IDH, 2008, pp. 8-9).

Para la supervisión de cumplimiento de 8 de julio de 2009, el Estado comunicó sobre 24 reuniones del MOS con participación de las víctimas, además de la amplitud del plazo de ejecución, extendido hasta diciembre de 2009 para permitir el seguimiento continuo de las demás medidas, considerando cumplida la orden, no obstante, la Corte mantendrá la supervisión del cumplimiento de su mandato abierto (Corte IDH, 2009, pp. 8-10).

\section{Sobre las órdenes con cumplimiento parcial}

El Estado debe investigar los hechos del caso, identificar, juzgar y sancionar a los responsables de la masacre. Para la supervisión del 8 de julio de 2009. El Estado solicitó respetar la no divulgación de las investigaciones adelantadas por la Fiscalía, en el entendido de poner en riesgo la investigación preliminar y que permanece según el régimen penal interno en reserva sumarial.

Ahora bien, para la Corte resulta del todo criticable la restricción de información, pues su función está lejos de constituirse en una instancia penal internacional que define responsabilidad individual, por lo que requiere conocer no solo los avances de los procesos contenciosos para establecer el cumplimiento de la orden dictada (Corte IDH, 2009, pp. 1012). Para la supervisión de cumplimiento del 26 de noviembre de 2008 ,
El Estado informó que se realizaron reuniones en el marco del MOS con el fin de coordinar diferentes temas relativos a la investigación de los hechos, como la protección de testigos, la individualización de nuevas víctimas y la estrategia de investigación. La investigación se encuentra a cargo de la Fiscalía General de la Nación y el Consejo Superior de la Judicatura (Corte IDH, 2008, p. 9).

Sin embargo, para la Corte siguiendo la réplica de los representantes de las víctimas y lo sostenido por la Comisión, aún luego de vincular a siete paramilitares a las investigaciones, la averiguación sobre los altos mandos militares resta desierta, además de ausencia de ejecución de órdenes de capturas que estaban vigentes aún antes de ser dictada la sentencia contra Colombia (Corte IDH, 2008, pp. 9-10).

Identificación de las víctimas de la masacre de Mapiripán y sus familiares. Quizá resulte la medida más controvertida y con mayor número de resoluciones, debido a la tacha de falsedad de algunas víctimas reconocidas e indemnizadas. En la resolución de supervisión de cumplimiento del 8 de julio de 2009, la Corte indica que el Estado reporta que se hicieron avances en el cumplimiento de esta medida, los resultados obtenidos, esto es, según la Fiscalía que para junio de 2008, se hayan ubicado a diez posibles familiares de víctimas, además de indicar que el MOS se acordó prorrogar el plazo establecido hasta diciembre de 2009, para que nuevas víctimas y familiares de estas se acerquen para su debida identificación (Corte IDH, 2009, pp. 18-19). Pese a las exhumaciones llevadas a cabo dentro de la Ley de Justicia y Paz y la ampliación del plazo que estipularon las partes a diciembre de 2009, siguen siendo insuficientes si se tiene presente la dimensión de la masacre y la cantidad de víctimas.

Programa de reparación de atención en salud integral. Para la supervisión de cumplimiento del 26 de noviembre de 2008 se sostiene que

El Estado se remitió a un informe presentado dentro del caso de la masacre de Pueblo 
Bello, puesto que el acuerdo realizado entre el Ministerio de Protección Social y el Programa de Naciones Unidas para el Desarrollo explicado en dicho informe, se aplicaría al cumplimiento de esta sentencia.

Además se señala por parte del Estado que "tiene a disposición de los familiares de las víctimas que requieren atención urgente, un mecanismo de apoyo con el Ministerio de Protección Social, pero a esa fecha ninguna solicitud ha sido presentada en este sentido" (Corte IDH, 2008, p. 11).

Para el 8 de febrero de 2012, la Corte anuncia en la resolución de supervisión de cumplimiento que en audiencia privada del 19 de mayo de 2010, el Estado entregó el 2 julio de 2010 un reporte sobre el avance "propuesta de implementación de las medidas de reparación de atención médica y psicológica" (Corte IDH, 2012, p. 3); sin embargo, los representantes de las víctimas sostienen entre otras críticas a la propuesta que "es necesario que el Estado otorgue una atención que sea i) preferencial; ii) gratuita; iii) completa $e$, iv) integral" y no resulta garantizado dentro del contrato con Caprecom que ha formulado (Corte IDH, 2012, p. 4).

También se informa sobre un proceso de concertación durante el año 2011, que tras un acuerdo denominado "Acta de entendimiento sobre el cumplimiento sobre la atención médica y psicológica" y la presentación de una "ruta de atención a víctimas", culmina con críticas por parte de la Comisión Interamericana respecto de omisiones en materia de "impacto diferenciado de los beneficiarios de las medidas y los demás usuarios de la seguridad social", indicando la necesidad de no confundir "la prestación de los servicios sociales que [el Estado] brinda a los individuos con las reparaciones a las que tienen derecho las víctimas de las violaciones de derechos humanos". Supervisión que concluye con un llamamiento de audiencia privada solicitada por la propia Comisión (Corte IDH, 2012, pp. 4-8).

Realizar las acciones necesarias para garantizar las condiciones de seguridad para que los familiares de las víctimas, así como otros expobladores de Mapiripán, que se hayan visto desplazados, puedan regresar a Mapiripán, en caso de que así lo deseen. Ya para la resolución de supervisión de cumplimiento de 26 de noviembre de 2008, el Estado advirtió que

El cumplimiento de esta medida se encuentra a cargo de la Agencia Presidencial Acción Social, entidad que [forma] parte del MOS y que, en el marco de este mecanismo, se estableció un plan de acción que se llevará a cabo para su cumplimiento, en consideración de que los representantes manifestaron que las víctimas no desean regresar a Mapiripán por el momento (Corte IDH, 2008, p. 11).

También se manifiesta la negativa de retorno por motivos de seguridad y el interés de las víctimas de ser reubicadas en otras regiones del país. En la supervisión de cumplimiento del 8 de julio de 2009:

El Estado señaló que no puede precisar si actualmente todas las personas desplazadas quieren retornar, porque muchas no se han localizado, a pesar de la convocatoria abierta. Los representantes valoraron algunos esfuerzos institucionales que se han dispuesto para cumplir con esta medida, como el diseño de un plan de acción y la integración del Comité tripartito, pero estas acciones no son suficientes y urge el diseño de estrategias complementarias para su satisfacción (Corte IDH, 2009, pp. 21-22).

La Corte reconoce los esfuerzos del Estado e indica el necesario respeto a la voluntad de la víctima, y pide profundizar en las medidas precisas a adoptar en materia de seguridad en caso de retorno o de reubicación.

Construir un monumento apropiado y digno para recordar los hechos de la masacre de Mapiripán. En la supervisión de cumplimiento del 8 de julio de 2009 
Se ha acordado que durante el 2009 se iniciará un proceso de concertación sobre los criterios del monumento, el artista, el lugar y los tiempos para que en diciembre de 2009 ya se tengan algunos avances y en el 2010 se pueda realizar la construcción del mismo.

La Corte advierte que el atraso en la construcción del monumento forma parte de un acuerdo entre víctimas y Estado, quienes convinieron que este se hará cuando se individualicen e identifiquen todas las víctimas (Corte IDH, 2009, p. 23).

Pago de indemnizaciones por daño material e inmaterial, costas y gastos. En la supervisión de cumplimiento con fecha de 26 de noviembre de 2008, el Gobierno colombiano informó que

[...] mediante resolución de 3 de mayo de 2007, el Ministerio de Defensa Nacional ordenó el pago de indemnizaciones a los familiares, lo cual fue aceptado por los representantes en sus últimas observaciones. Además, el Estado realizó el pago de indemnizaciones a los familiares de Ledwin Morales, una de las víctimas no identificadas en la sentencia (Corte IDH, 2008, p. 14).

\section{Conclusiones}

En relación con la valoración de la prueba para condenar podemos indicar que en el caso de la Masacre de Mapiripán vs. Colombia el Estado se refirió a ciertas pruebas testimoniales como incoherentes, y dicha observación no se tuvo en cuenta, claro está, que desde el principio jurisprudencial internacional de la "amplia flexibilidad en la valoración de la prueba", la Corte está plenamente facultada para interpretar el acervo probatorio con los presupuestos de la lógica y la experiencia, por dicho principio, la Corte IDH no se encontraba obligada a considerar la observación negativa que efectuó el Estado frente a algunas pruebas documentales.

En el contencioso ante la Corte IDH finalmente se revisan las obligaciones de los Estados frente a la Convención, estos se toman como el único sujeto de responsabilidad internacional dentro del modelo interamericano, tal situación ha permitido que las declaraciones de responsabilidad del propio Estado sean consideradas con pleno valor jurídico y por lo mismo indiscutibles desde el punto de vista probatorio.

Por ello, es relevante destacar el valor irrefutable de la aceptación de responsabilidad estatal, pues da lugar al cierre de la discusión sobre lo que el Estado acepta, ya sea en relación con los hechos, las víctimas o los agentes responsables. En el caso particular de la masacre de Mapiripán, Colombia hizo uso de esta figura, pieza importante en el caso, para el cierre del análisis probatorio y la definición de la condena contra el Estado colombiano.

Queda claro que el reglamento de la Corte IDH, desde su creación hasta el día de hoy, se ha modificado en numerosas ocasiones para que la Corte realice un mejor trabajo en la recolección y valoración de la prueba. Pero los avances en los reglamentos son mínimos y dejan muchos vacíos, los cuales la misma Corte ha entrado a llenarlos a través de su jurisprudencia, por medio de las sentencias dictadas se han establecido principios que rigen en materia de valoración de las pruebas. Evidentemente se presenta un contraste en cuanto al mínimo desarrollo normativo en materia probatoria del reglamento y el gran desenvolvimiento jurisprudencial de la Corte.

Por todo lo anterior y por la revisión de los reglamentos y la jurisprudencia de la Corte IDH, resulta válido aseverar que existe un diseño de modelo probatorio que se enmarca en una concepción notoriamente interamericana de lo que se considera son los medios de prueba válidamente aceptados para demostrar las violaciones de derechos humanos, las presunciones de aceptación de responsabilidad internacional del Estado y los mecanismos de interpretación a los que los jueces pueden acercarse para estimar como probada la existencia de una violación de los deberes y obligaciones de la Convención y por ello la responsabilidad internacional del Estado. 
En cuanto al estado de cumplimiento de las órdenes contenidas en la sentencia, se concluye que: las críticas contra el sistema de supervisión de cumplimiento de la Corte fueron dirigidas por el señalamiento de falsas víctimas reconocidas por la Corte misma, basadas en la aceptación del Estado y sobre quienes se ordena cumplir la condena. El proceso de pago de las reparaciones pecuniarias se ve ahora ensombrecido por la ausencia de individualización e identificación que el mismo Estado debía ejecutar como una exigencia prevista dentro de las medidas de satisfacción y no repetición, que se estima en un cumplimiento parcial.

Siendo solo una de las nueve medidas ordenadas, y sobre las que la Corte reconoce cumplimientos parciales, y entendiendo que solo tres de las nueve órdenes se han aceptado como cumplimiento total de lo contenido en la sentencia, podemos indicar que el nivel de cumplimiento es del 33,3\%, restando a diciembre de 2013; ocho años después de ser dictada la sentencia condenatoria seis órdenes por ejecutar totalmente, que equivalen al $66,7 \%$ y que se registran como cumplimiento parcial y no como incumplimiento, pues el Estado demostró haber adelantado trámites internos para la plena puesta en práctica de las medidas ordenadas sin que haya podido en muchas ocasiones celebrar acuerdos con los representantes de las víctimas para su ejecución.

Sin duda, el reconocimiento y declaración de falsas víctimas incluidas dentro de las reconocidas por el Estado y la Corte, tiene un efecto no deseado sobre la ejecución de la sentencia, pues el clima de desconfianza entre las partes: representantes de las víctimas, Estado y Comisión reduce oportunidades rápidas de acuerdos para lograr las condenas impuestas por la violación de derechos humanos.

\section{Referencias}

Amaya, Á. F. (2007). "Efecto reflejo": la práctica judicial en relación con el derecho a la verdad en la jurisprudencia de la Corte Interamericana de Derechos Humanos.
International Law: Revista Colombiana de Derecho Internacional, noviembre, pp. 131-152. Disponible en: http://www. redalyc.org/articulo.oa?id $=82401005$

Huertas, O., Cáceres, V., Chacón N., Gómez, W., Castellanos, E. y Sanabria, J. (2006). Colombia ante la Corte Interamericana de Derechos Humanos: recuperación de la memoria histórica: 1995-2006. Bogotá: Ibáñez.

Landman, T. (2011). Política comparada, una introducción a su objeto y métodos de investigación. Madrid: Alianza.

Marquardt, B. (2009). La ciencia del constitucionalismo comparado, aproximación metodológica a una rama de la historia política que debería ser escrita. En: Constitucionalismo comparado, acercamientos metodológicos, históricos y teóricos. Marquardt. B. (Ed.). Bogotá: Universidad Nacional de Colombia. pp. 1- 137.

Marquardt, B. (2014). Historia del Estado moderno en Asia y África del Norte (15002014). Bogotá: Universidad Nacional de Colombia.

Rodríguez, I. (2014). Despojo, baldíos y conflicto armado en Puerto Gaitán y Mapiripán (Meta, Colombia) entre 1980 y 2010. Estudios Socio-Jurídicos, 16(1), pp. 315342. Disponible en: http://www.scielo.org. co/pdf/esju/v16n1/v16n1a09.pdf

Romero, X. (2009). El reconocimiento parcial de la responsabilidad del Estado colombiano en el Sistema Interamericano de Derechos Humanos. Casos Mapiripán, Ituango y La Rochela. Anuario Mexicano de Derecho Internacional, 9, pp. 219-243. Disponible en: http://www.scielo.org.mx/ scielo.php?script $=$ sci_arttext\&pid $=\mathrm{S} 1870$ 46542009000100008 \&lng $=$ es\&tlng $=e s$

Uribe, C. \& Restrepo, N. (2013). Could the Interamerican Human Rights System have prevented ted the existence of false victims in the Mapiripán Case? International Law, Revista Colombiana de Derecho Internacional, 23, pp. 203-234. Disponible en: http://www.scielo.org.co/ scielo.php?script $=$ sci_arttext\&pid=S169281562013000200007\&lang $=$ pt 
Vivas, T. (2013). Comparar, un método de análisis jurídico. En: B. Marquardt (ed.). Constitucionalismo científico II, entre el Estado y el mercado (429-450). Bogotá: Temis.

\section{Jurisprudencia}

Corte Interamericana de Derechos Humanos. (1988). Informe anual. Anexo I. Disponible en: http://www.corteidh.or.cr/sitios/ informes/docsSPA/spa_1988.pdf

Corte Interamericana de Derechos Humanos. (21 de enero de 1994). Caso Gangaram Panday vs. Surinam. Sentencia.

Corte Interamericana de Derechos Humanos. (19 de enero de 1995). Caso Neira Alegría y otros vs. Perú. Sentencia.

Corte Interamericana de Derechos Humanos. (8 de diciembre de 1995). Caso Caballero Delgado y Santana vs. Colombia. Sentencia.

Corte Interamericana de Derechos Humanos. (17 de septiembre de 1997). Caso Loayza Tamayo vs. Perú. Sentencia.

Corte Interamericana de Derechos Humanos. (12 de noviembre de 1997). Caso Suárez Rosero vs. Ecuador. Sentencia.

Corte Interamericana de Derechos Humanos. (8 de marzo de 1998). Caso de la "Panel Blanca" (Paniagua Morales y otros) vs. Guatemala. Sentencia.

Corte Interamericana de Derechos Humanos. (5 de febrero de 2001). Caso "La última tentación de Cristo" (Olmedo Bustos y otros) vs. Chile. Sentencia.

Corte Interamericana de Derechos Humanos. (31 de agosto de 2001). Caso de la Comunidad Mayagna (Sumo) Awas Tingni vs. Nicaragua. Sentencia.

Corte Interamericana de Derechos Humanos. (27 de noviembre de 2003). Caso Maritza Urrutia vs. Guatemala. Sentencia.

Corte Interamericana de Derechos Humanos. (5 de julio de 2004). Caso 19 comerciantes us. Colombia. Sentencia.

Corte Interamericana de Derechos Humanos. (2 de septiembre de 2004). Caso "Instituto de Reeducación del Menor" vs. Paraguay. Sentencia.

Corte Interamericana de Derechos Humanos. (15 de septiembre de 2005). Caso La Masacre de Mapiripán vs. Colombia. Sentencia.

Corte Interamericana de Derechos Humanos. (1 de julio de 2006). Caso de las Masacres de Ituango vs. Colombia. Sentencia.

Corte Interamericana de Derechos Humanos. (26 de septiembre de 2006). Caso Almonacid Arellano y otros vs. Chile. Sentencia de excepciones preliminares, fondo, reparaciones y costas.

Corte Interamericana de Derechos Humanos. (8 de julio de 2009). Caso de la Masacre de Mapiripán vs. Colombia. Supervisión de cumplimiento de sentencia. Resolución.

Corte Interamericana de Derechos Humanos. (24 de noviembre de 2009). Caso Masacre de Las Dos Erres vs. Guatemala. Sentencia.

Corte Interamericana de Derechos Humanos. (8 de febrero de 2012). Caso de la Masacre de Mapiripán vs. Colombia. Supervisión cumplimiento de sentencia. Resolución.

Corte Interamericana de Derechos Humanos. (23 de noviembre de 2012). Caso de la Masacre de Mapiripán vs. Colombia. Supervisión de cumplimiento de sentencia. Resolución.

Corte Interamericana de Derechos Humanos. (28 de noviembre de 2012). Caso Artavia Murillo y otros ("Fecundación in vitro") vs. Costa Rica. Sentencia.

Corte Interamericana de Derechos Humanos. (30 de noviembre de 2012). Caso Masacre de Santo Domingo vs. Colombia. Sentencia.

\section{Estatutos, leyes y reglamentos}

Corte Interamericana de Derechos Humanos. (1980). Reglamento. Disponible en: http:// www.corteidh.or.cr/sitios/reglamento/1980. pdf

Corte Interamericana de Derechos Humanos. (1991). Reglamento. Disponible en: http:// www.corteidh.or.cr/sitios/reglamento/1991. pdf 
Corte Interamericana de Derechos Humanos. (1996). Reglamento. Disponible en: http:// www.corteidh.or.cr/sitios/reglamento/1996. pdf

Corte Interamericana de Derechos Humanos. (2000). Reglamento. Disponible en: http:// www.corteidh.or.cr/sitios/reglamento/2000. pdf
Corte Interamericana de Derechos Humanos. (2003). Reglamento. Disponible en: http:// www.corteidh.or.cr/sitios/reglamento/2003. pdf

Corte Interamericana de Derechos Humanos. (2009). Reglamento. Disponible en: http:// www.corteidh.or.cr/sitios/reglamento/ ene_2009_esp.pdf 